\title{
Constructing a Financial Condition Index for a Small-Open Economy: The Case of Malta
}

\author{
Borg $\operatorname{Ian}^{1, *} \&$ Micallef Brian ${ }^{2}$ \\ ${ }^{1}$ Senior Economist, Economic Analysis Department, Central Bank of Malta, Malta \\ ${ }^{2}$ Manager, Research Department, Central Bank of Malta, Malt \\ *Correspondent author: E-mail: borgi@centralbankmalta.org
}

Received: July 20, 2018 Accepted: August 30, 2018 Published: September 20, 2018

doi: 10.5296/rae.v10i3.13755 URL: https://doi.org/10.5296/rae.v10i3.13755

\begin{abstract}
This paper develops a Financial Conditions Index (FCI) for Malta for the period 1996-2017. This index provides a summary measure of financial conditions by combining several financial variables, both domestic and foreign, that influence economic activity. The indicators in the FCI are grouped in four categories: interest rates, bank balance sheet, asset prices and external variables. The weights are derived using Principal Component Analysis (PCA) and cross-checked using simulations from STREAM, the Central Bank of Malta's macro-econometric model. Financial conditions in Malta were relatively benign in the mid-to-late 90s, followed by a period of tightening in the early 2000s. Financial conditions improved again during the pre-crisis period but deteriorated during the financial crisis and remained tight until 2013. In recent years these have recovered and became broadly neutral by 2017 . The proposed FCIs correlate the most with one to three quarters ahead real GDP growth, suggesting potential predictive capacity for short-term forecasting.
\end{abstract}

Keywords: financial conditions index, PCA, short-term forecasting

JEL Classification: B26; C3; C38; E44; 


\section{Introduction}

A financial conditions index (FCI) provides a summary measure of domestic financial conditions by combining several financial variables that influence economic activity. These financial variables comprise a number of indicators that capture the various channels through which monetary policy is transmitted to the real economy and, ultimately, inflation. These indices are becoming increasingly used both for financial surveillance and forecasting.

The importance of the various transmission channels depends, to a large extent, on the structure of the financial system. For instance, firms in Malta are more dependent on bank financing compared to their counterparts in the euro area, where the corporate bond market and equities play a more important role. At the same time, firms in the euro area are less reliant on the equity market compared to their US counterparts. According to the Survey on Access to Finance of Enterprises (SAFE), around 75\% of Maltese SMEs in 2015 considered bank financing as the most relevant source of external financing compared to around $55 \%$ of European SMEs (Zerafa, 2016). Domestic SMEs are also more dependent than their European counterparts on bank overdrafts, credit lines and credit card facilities.

The Maltese banking sector emerged relatively unscathed from the 2009 financial crisis and the 2012 European sovereign debt crisis. No financial institution required government support and liquidity and capital ratios of the core banking system remained well above regulatory minimum. The correction in the housing market has however led to an increase in non-performing loans (NPLs), which were mainly concentrated in construction and real estate sectors. In addition, despite strong economic and employment growth, credit to the private sector slowed down significantly after the financial crisis and a negative 'credit gap' opened up between 2012 and 2014 (Micallef, 2015). The contraction in credit was driven mainly by loans to non-financial corporations (NFCs) and to households for consumption purposes whereas credit for mortgages continued to grow, albeit at a slower rate. Robust growth and the rebound in the house price cycle after 2013 did not led to an increase in bank credit to NFCs, with this process of disintermediation being driven by both demand and supply side factors (Darmanin, 2017). The monetary easing by the European Central Bank was imperfectly transmitted to bank retail rates and the pass-through for lending rates to NFCs and deposits became more sluggish after the crisis (Micallef et al, 2016). More recently, buoyant economic activity led to large increases in bank deposits and a recovery in property prices, with the latter being also influenced by government policies and socio-demographic changes (Micallef, 2018).

Against this background, this paper develops an FCI to evaluate financial conditions in Malta. A total of 11 variables are includes, which are grouped in four categories - interest rates, bank balance sheet indicators, asset prices and external variables. The weights are derived using Principal Component Analysis (PCA), a statistical approach intended to collapse a large set of variables into a single indicator. In addition, the results are cross-checked using simulations from STREAM, the Central Bank of Malta's macro-econometric model.

The main findings are summarised as follows. Financial conditions move in cycles - they were benign in the mid-to-late 1990s and the pre-crisis period but tight in the early 2000s and 
during the financial crisis. Financial conditions remained tight until 2013, although they have recovered somewhat in recent years. The proposed FCIs correlate the most with one to three quarters ahead real GDP growth, suggesting potential predictive capacity for short-term forecasting.

The rest of the paper is organised as follows. Section 2 provides a brief overview of the literature. Section 3 documents the methodology and the data used, while Section 4 presents the results. Section 5 outlines an alternative index using simulations from STREAM and section 6 takes a cross-country comparison. Section 7 discusses the relationship of the financial condition indices with economic activity and section 8 concludes.

\section{Literature Review}

The interest in macro-financial linkages emanated from the academic observation that financial frictions in an economy can both cause macroeconomic fluctuations and amplify these shocks (Quadrini, 2011). Despite the significant theoretical contributions in this respect, notably through the incorporation of financial frictions in general equilibrium models (Bernanke and Gertler, 1989; Kiyotaki and Moore, 1997; Carlstrom and Fuerst, 1998; Bernanke, Gertler, and Girlchrist, 1999), it is only recently that macro-economic models in policy circles have been explicitly linking financial variables to the macro-economy. The global financial crisis of 2008/09 has prompted a fundamental re-evaluation of the need to properly take into consideration the linkages between the financial sector and the real economy (Gerali et al, 2010; Bokan et al, 2018; Gertler and Karadi, 2011). In part, this was triggered by the fact that many models commonly used in policy circles before the crisis largely assumed frictionless financial markets (Smets and Wouters, 2003; Christoffel et al. 2008).

Indices of financial conditions have a long history. Traditionally, the main interest in policy circles has been to capture the monetary policy transmission mechanism. The Bank of Canada has been at the forefront of this strategy, by developing a Monetary Conditions Index (MCI) to assess the transmission mechanism. In its simplest form, MCIs take a weighted average of interest rates and exchange rates to summarise the impact of monetary policy changes through these two channels (Freedman, 1995).

The original MCI was, however, very limited in scope. As financial systems became increasingly more sophisticated, the adequate characterisation of these systems, their impact on financing costs and eventually on macroeconomic variables required the inclusion of a broader set of financial variables. Additional variables such as the long-term interest rate, equity prices and house prices, were subsequently introduced to capture more channels of monetary policy. For instance, Goodhart (2001) and Mayes and Viren (2002) include both equity and house prices in their financial conditions indices, since these variables are found to explain fluctuations in the output gap. Similarly, Gauthier et al. (2004) augments a standard data set with asset prices and the bond yield risk premium.

The inclusion of additional variables brought about added complexities in the methodological framework. A wide range of methodologies for constructing such indices has been developed 
over time, but the most popular are the weighted-sum approach and the PCA.

In the weighted-sum approach, the weights of each financial indicator are assigned according to the estimated impact on a macroeconomic variable, usually real GDP growth, the output gap or inflation. These are typically estimated either in a vector autoregressive framework (VAR), reduced-form demand equations or structural macroeconomic models.

One of the earlier approaches in this strand of literature is the IS-curve method, in which the output gap is regressed against its own lags, inflation, and financial variables. The weights are set equal to the coefficients estimated on the financial variables (Mayes and Viren, 2002). Gauthier et al. (2004) employ a similar framework for their FCI but add a Phillips curve to include the impact on inflation. These approaches are thus concerned with establishing and directly estimating the link between financial variables and output and inflation.

Other studies calibrate the weight of financial variables in FCIs using simulations from large-scale macroeconomic models. Guichard et al. (2009) calibrate FCIs for the euro area, Japan and the United Kingdom, based on estimated weights for the United States. The weights are in turn derived from weights estimated from a combination of VAR impulse response shocks and macroeconomic simulations using the FRB/US model in Guichard and Turner (2008). Similarly, Dudley and Hatzius (2000) simulate shocks using the FRB/US model to derive their weights for the Goldman Sachs FCI.

VAR models have also gained popularity in deriving the weights for FCIs, primarily because they are particularly suited to capture the relationships between macro and financial variables. Goodhart and Hoffman (2000) utilise a panel VAR to derive weights from a panel of 17 industrialised countries, identifying their shocks using Choleski decomposition. The same approach is used by Swiston (2008) and Ho and Lu (2013) for the US and Poland, respectively. On the other hand, Gauthier et al. (2004) and Osorio et al. (2011) use generalised impulse response functions to circumvent the problem of the ordering of the variables in the VAR commonly faced when using the Choleski decomposition or similar restrictions. In most cases, the weight attached to the financial variables is obtained as the cumulative response, typically between 4 to 6 quarters, of GDP growth to a one unit shock to the financial variables included in the VAR.

The main attraction of the weighted-sum approach is the direct link between financial variables and the real economy. Nevertheless, they are often faced with the so-called curse of dimensionality, in that degrees of freedom are quickly consumed as more variables are added to the system. As previously explained, modern financial systems are complex and their adequate characterisation requires the inclusion of a broad set of variables.

The PCA approach is able to circumvent the curse of dimensionality by extracting a common factor that captures the greatest common variation in a broad set of variables (Stock and Watson, 2002). The main advantage of the PCA is its practicality, as it facilitates the collapse of a large set of financial variables into a single indicator. This approach is however largely a theoretical. As a purely statistical tool, the major disadvantage of this method is its assumption that the indicators with the greatest variability have the biggest economic significance. Furthermore, some indicators could turn out with a "wrong" sign and will have to be excluded from the model. 
Angelopoulou et al. (2014) use the PCA approach to construct an FCI for euro area countries using a wide range of prices, quantities, spreads and survey data. Osorio et al (2011) use a similar approach to provide a quantitative assessment of overall financial conditions in 13 Asian economies. The PCA approach is increasingly used in the construction of indices to measure financial stress (Hakkio and Keeton, 2009; Micallef, 2016). Hatzius et al. (2010) control for past GDP growth and inflation, and focus on the predictive power of financial conditions for future economic activity. The latter approach has become very common in this strand of the literature (Onsorio et al. 2011; Ho and Lu, 2013). Darracq Pariès et al. (2014) construct an FCI for the euro area and selected large euro area countries to identify credit supply shocks within a Bayesian VAR framework.

Most of the FCIs constructed in the literature appear to have good leading indicator properties. In particular, most of these indices tend to improve the forecasting performance of simple VAR models of economic activity while they also appear to contain important information useful to forecast turning points (Gauthier et al. 2004; Wacker et al. 2014). On the contrary, the evidence on the forecasting content of FCIs for inflation appears to be mixed (Goodhart and Hofmann, 2000; English et al. 2005).

\section{Methodology}

\subsection{Data}

The importance of the various transmission channels depends on the structure of the domestic financial system. Hence, the dataset utilised to construct the FCI attempts to replicate the primary features of the Maltese financial system, which in turn determines the state of financing conditions.

As is typical in these exercises, we started with a fairly large dataset which was subsequently reduced using the two following criteria: (1) the sign corresponding to the first principal component has to be economically meaningful; (2) the time span should start from the mid-1990s to capture the tight financial conditions of the early 2000s.

A total of nine domestic variables are included in the index: real credit, real deposits, real equity prices, issues of securities and shares, the non-performing loans (NPLs) ratio, the retail interest rate on deposits, the spread between the lending rate and the policy rate, the spread between Malta's ten-year government bond yield and the ten-year bund yield (defined below as the 'Sovereign spread') and the return on equity of the banking system. Foreign influences are captured through the Composite Indicator of Systemic Stress (CISS), which is intended to capture systemic stress in the euro area's financial system and the Eurostoxx 50 as a measure of equity prices in the euro area.

Trending variables were transformed into stationary ones by taking the year-on-year growth rates. Additionally, all variables were standardised.

\subsection{Methodology}

Using the eigenvalue-eigenvector decomposition, PCA is able to decompose the covariance 


\section{Macrothink

structure into the common and idiosyncratic component. The largest eigenvalue corresponds to the maximum variance in the matrix of variables and the eigenvectors are directions that correspond to the largest eigenvalue. The first principal component thus corresponds to the unit-length linear combinations of the variables that correspond to the largest eigenvalue. Each subsequent principal component corresponds to the remaining variance not explained by the previous principal component and orthogonal to the previous principal component.

The derived first principal component reflects both the impact of demand and supply on the evolution of the financial variables. However, financing conditions should be interpreted as a representation of financial shocks and therefore, the FCI should be stripped from the feedback of economic activity. Following Gumata et al. (2012), this endogeneity problem is addressed in the second stage of the estimation, when we purge the first principal component of this feedback by regressing it on current GDP growth in Malta and the euro area. The residual of this regression is taken as our estimated FCI measure for Malta. As a result, the 'purged' FCI reflects only the exogenous shifts in the financial conditions.

\section{Results}

\subsection{Weights}

Figure 1 plots the factor loadings derived from the PCA. The foreign variables have a relatively large weight in Malta's FCI reflecting the open nature of the Maltese economy. In terms of the domestic variables, given that Malta's financial system is primarily bank-based, real credit has the largest positive weight, while interest rate spreads have the largest negative weight.

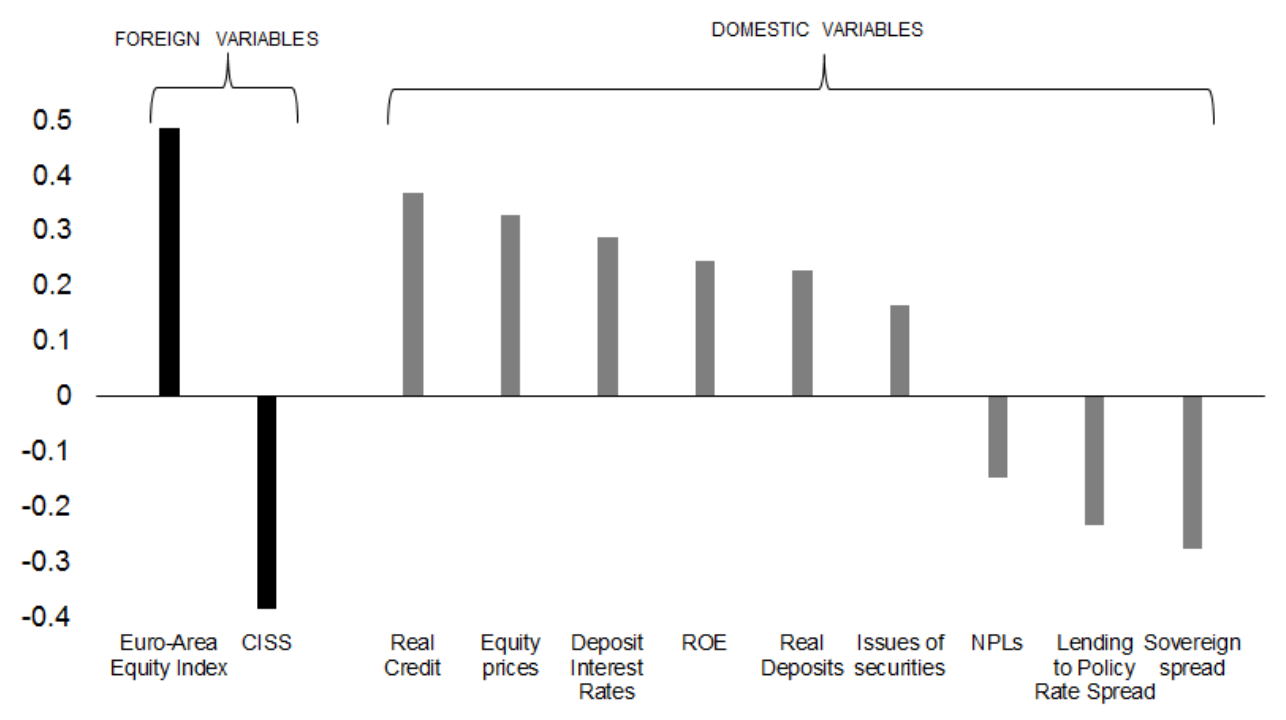

Source: Authors' Calculations

Figure 1. Factor Loadings 


\section{Macrothink}

\subsection{FCI}

Figure 2 plots the FCI and the contributions of the financial variables to the first principal component. The individual indicators are grouped into four categories, covering the external variables (CISS and euro area equity prices), bank balance sheet indicators (bank credit and deposits, ROE and NPLs), interest rates and spreads (deposit interest rate, sovereign spread and the spread between the lending and the policy rate) and the others (equity prices and issues of NFC securities).

Financing conditions in Malta exhibit a clear cyclical pattern. Financing conditions in the mid-to-late 90s were accommodative, boosted by strong real credit growth and benign conditions from abroad. Buoyant equity prices played an important role at the turn of the millennium. In the early 2000s, however, financing conditions tightened as the economy was hit by a combination of demand and supply shocks, which resulted in a drop in credit growth and an increase in NPLs following the introduction of stricter regulatory requirements, which required banks to make additional provisions, with an adverse impact on their capital and profitability Moreover, the external factors affecting financing conditions also tightened considerably during this period as the bursting of the dot-com bubble and the terrorist attacks of 9/11 heightened international financial stress, which in turn depressed equity markets, both locally and abroad. In Malta, the equity price index declined by $51 \%$ from its peak in early 2000 until its trough at the end of 2002, driven mainly by the banking sector and a major firm in the telecommunications industry.

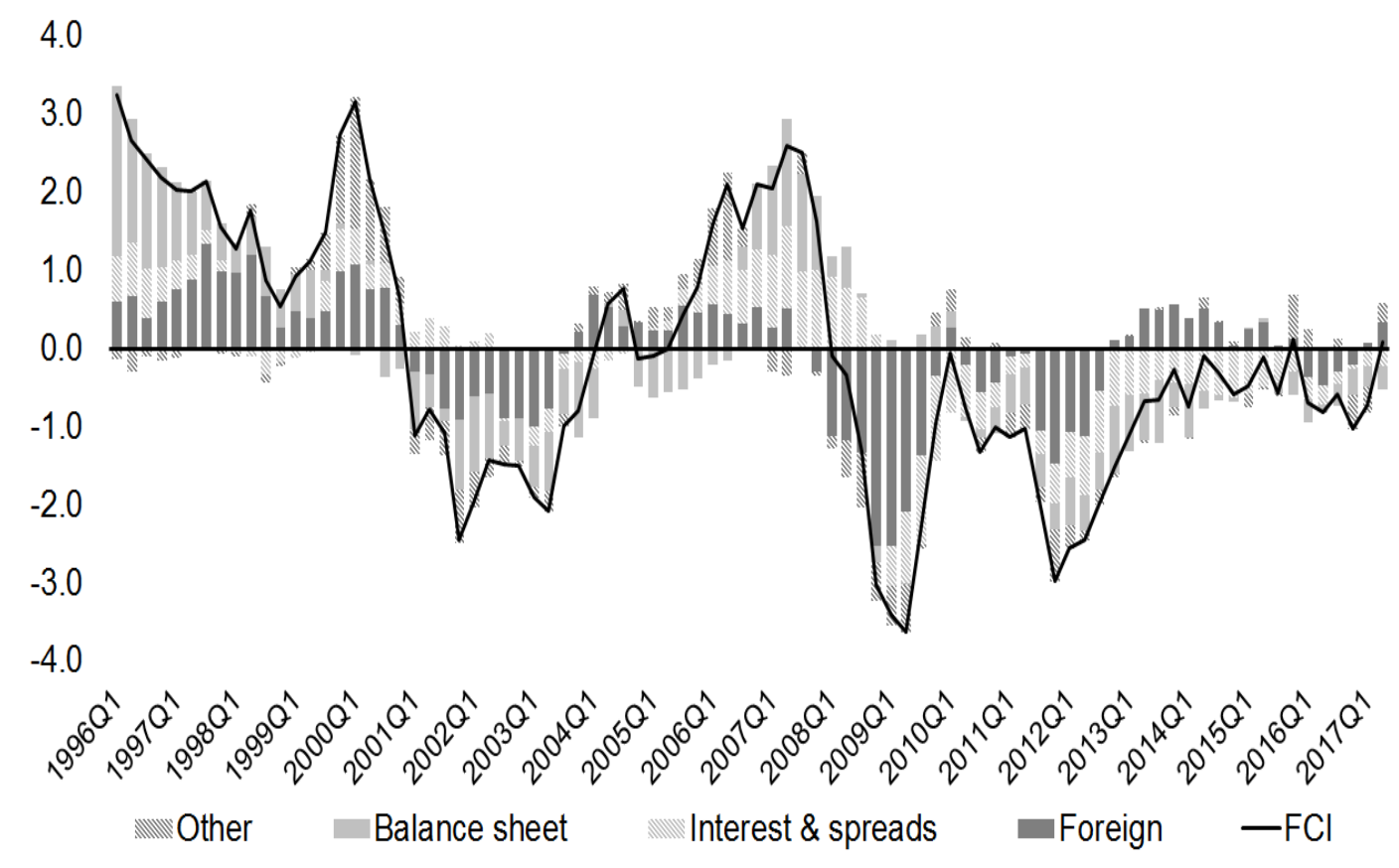

Source: Authors' Calculations

Figure 2. Contributions to the Financial Conditions Index. (percentage point contributions) 


\section{MInstitute ${ }^{\text {Mink }}$}

Conditions started to improve again in the pre-crisis cyclical upswing before being tightened considerably in 2008 driven by the onset of the financial crisis, with heightened stress in international markets, as well as the drop in real credit growth and the rise in risk premiums.

After recovering in 2010, domestic financing conditions tightened again in 2012-2013 primarily due to the decline in credit growth, as well as the intensification of the sovereign debt crisis in the euro area. The decline in credit growth was not supported by demand-related factors since economic performance during this period was relatively robust. The relatively tight financing conditions experienced in 2013 are in part also related to the impaired transmission mechanism of monetary policy, reflected in wider spreads (Micallef et al., 2016).

Starting from early 2014, however, financial conditions improved significantly driven by the reduction in foreign stress, and facilitated by additional monetary easing by the European Central Bank. On the other hand, domestic variables generally continued to weigh down as the negative contribution of credit growth, the increase in NPLs and wider credit spreads persisted, and were only partly offset by improvements in real deposit growth.

\subsection{Purged FCI}

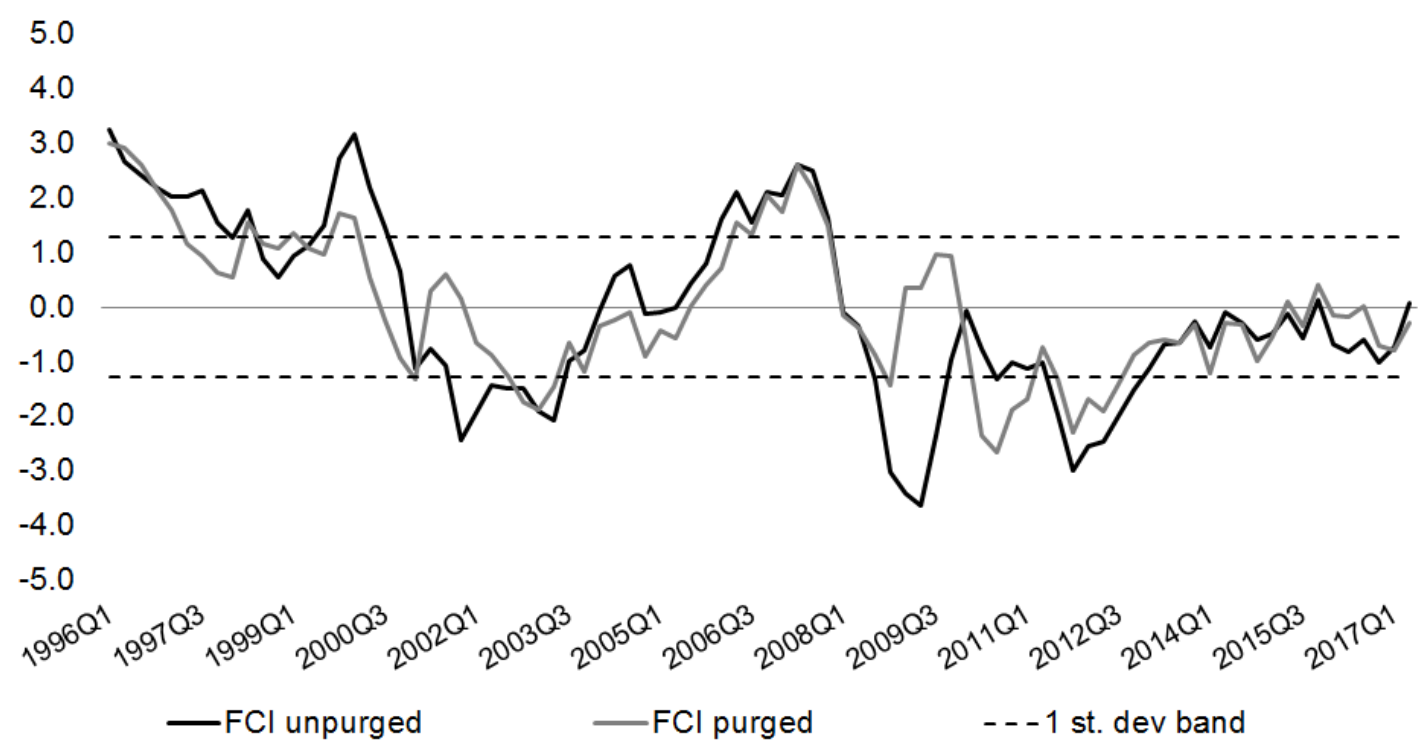

Source: Authors' Calculation

Figure 3. FCI - Purged and Unpurged

Figure 3 plots the FCI purged from the impact of macroeconomic conditions on financial variables, thus representing exogenous financial shocks. As explained in Section 3.1, the purged FCI is obtained by taking the residuals from a regression of the first principal component on current GDP growth in Malta and the euro area. In most instances, the difference between the two series is minimal, except in two periods. In 2001-2002, the unpurged FCI goes into negative territory, signalling tight financing conditions, while the FCI purged from macro-economic influences remains broadly neutral. Similarly, in 2009, the 
unpurged FCI drops very strongly, but the decline in the purged FCI is much more muted. The main reason behind these differences is that some of the decline experienced in these two periods is explained by deterioration in economic activity, both domestic and international. Hence, the decline in the unpurged FCI in these two instances is partly demand-related rather than driven by financial supply shocks.

Figure 3 plots the two FCIs within a one standard deviation range to assess historical episodes in which financial conditions deviated substantially from its mean. Among these episodes, the mid-1990s as well as the period 2006-2007 were clearly characterised by accommodative financial conditions. On the contrary, financial conditions were tight after the financial crisis and, to a lesser extent, in the early 2000s. The period after 2013 is characterised by generally normal financing conditions, albeit biased towards the low end of the distribution.

\section{Sensitivity Analysis - Simulations Using STREAM}

The PCA is only a statistical technique intended to capture variations among a large set of variables, and therefore it is not always clear whether the derived weights are consistent with what one would expect for a particular economy. In addition, some variables that a priori might be expected to exert a significant role on financial conditions could display an incorrect sign and would therefore have to be excluded. In the case of Malta, house prices and the real effective exchange rate, two variables that are commonly included in the MCI/FCI literature, had to be excluded from the PCA-based FCI because they had the wrong sign.

To assess the robustness, we develop an alternative FCI using simulations from STREAM, the Central Bank of Malta's macro-econometric model of the Maltese economy, which in recent years has been enriched with detailed fiscal and banking sectors (Grech and Rapa, 2016). STREAM is a medium-scale model that strikes a reasonable balance between containing sufficient detail to capture the key economic relationships underpinning the Maltese economy, while at the same time remaining tractable and manageable. Alternative methods used in the literature, such as VARs, provided unsatisfactory results due to the short-time series of Maltese data.

The weights were derived from the response of real GDP growth after 4 to 6 quarters following a one standard deviation shock to each variable. The main difference with respect to the PCA method outlined above is the inclusion of house prices and the real effective exchange rate. The following variables (with weights in brackets) were used: real credit to the private sector $(25 \%)$, the real effective exchange rate $(17 \%)$, real house prices $(12 \%)$, real deposits $(5 \%)$, real equity prices $(5 \%)$, interest rates $(6 \%)$ and the NPL ratio $(5 \%)$. These variables are intended to capture the various channels - interest rates, exchange rate, asset prices, lending conditions - through which financing conditions affect the real economy. One limitation of STREAM is the absence of foreign financial variables, which are usually found to exert an important influence on domestic financing conditions in open economies. Given the small and open economy characteristics of the Maltese economy, we introduce CISS to capture systemic stress in the euro area, with its weight calibrated to $25 \%$. 


\section{Macrothink}

Figure 4 illustrates the range between the results obtained from the PCA (purged and unpurged) and the version from STREAM, together with the one-standard deviation bands. The FCI using STREAM broadly follows the dynamics from the PCA. The divergence in the period 2014-2015 is mostly explained by the depreciation of the exchange rate, which is excluded from the PCA approach. The exchange rate then appreciated in 2016 and the first half of 2017, which contributed negatively to the FCI. Similar to the FCI using PCA, it indicates broadly neutral financing conditions by the second quarter of 2017.

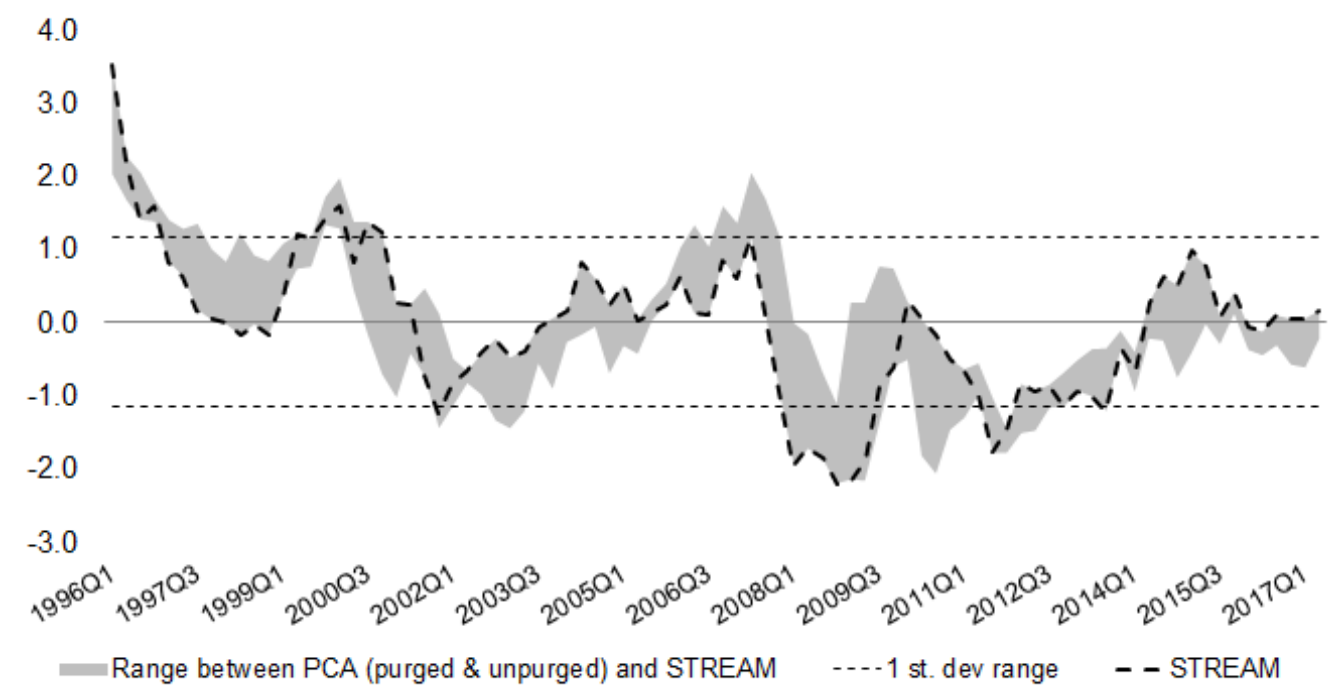

Source: Authors' Calculations

Figure 4. Sensitivity Analysis

\section{Cross-Country Comparison}

One of the useful features of a financing conditions index is that it provides a tractable way to compare the state of financing conditions across countries. Over time, financial systems have become increasingly interconnected and one can expect some level of co-movement between financial cycles across countries. That said, divergences could still occur for a number of reasons, such as differences in the monetary policy stance across countries or the health of the banking system. In this section we provide a brief overview of the FCIs published recently for the euro area, the United States, and other selected countries, and how these compare with Malta's FCI.

Financing conditions indices calculated by Angelopoulou et al. (2014), Baroussia et al. (2015), and Manning and Shamloo (2015) show that financial conditions in the euro area were quite loose in the pre-crisis period but started to tighten in early 2008 following the failure of Bear Sterns and deteriorated significantly after the collapse of Lehman Brothers in September 2008. After bottoming out in 2009, the recovery in euro area financial conditions was very volatile and muted. Fiscal concerns in 2011 and the intensification of the sovereign debt crisis in 2012 continued to create a tight financial environment, alleviated somewhat by non-standard measures (Darracq Pariès et al, 2014). Other studies document that the euro 
area experienced a prolonged period of tight financial conditions in the aftermath of the financial crisis, easing only by the end of 2014 (Manning and Shamloo, 2015).

Angelopoulou et al. (2014) focus on a number of individual countries in the euro area and find substantial divergences between Germany and other peripheral countries in the euro area. German financial conditions were looser than the euro area average in the pre-crisis period, while those in peripheral countries were relatively stable. All euro area countries experienced a sharp deterioration in their financing conditions in 2009 due to the uncertainty created by the financial crisis. Heterogeneities in financing condition re-emerged in the post-crisis period. Financing conditions remained very tight in countries such as Greece, Spain, Portugal, and Ireland, due to the effects of the sovereign debt crisis. Since Germany was not directly impacted by the sovereign debt crisis, its financing conditions recovered faster compared to the stressed economies, also driven by the non-standard measures adopted by the ECB.

Financial conditions in the United States over time were generally similar to those in the euro area. FCIs estimated by Guichard et al. (2009), Hatzius et al. (2010) and Wacker et al. (2014) show that the US experienced a general upswing in financial conditions in the period after the dot-com bubble and before the financial crisis. Financing conditions became very tight during the financial crisis but recovered faster than in the euro area as the Federal Reserve embarked on a more expansionary monetary policy stance and was not saddled by a sovereign debt crisis.

Financial conditions in Malta generally co-move with those of its main trading partners. Malta's financial conditions improved strongly before 2008, driven by both domestic and foreign variables, similar to the loosening experienced in the euro area and the United States. Moreover, although Maltese banks were not directly hit by the financial crisis due to their limited exposure to the subprime mortgage market, financing conditions in 2008 and 2009 followed those in other countries and became tight by historical standards. Initially, this was driven largely by foreign variables and, to a lesser extent, equity prices and widening spreads. After 2011, however, domestic factors played an increasingly important role. Although Malta was not affected by the sovereign debt crisis like other peripheral economies in Europe, and despite the strong growth in economic activity, domestic factors such as the decline in credit, the increase in NPLs and a sluggish interest rate pass-through continued to dampen the recovery in financial conditions.

\section{Relationship with Economic Activity}

A number of studies in the literature suggest that FCIs tend to have good leading indicator properties and therefore, could be used for short-term forecasting. Chart 5 plots the annual growth rate of real GDP with the range of FCIs for Malta. Despite the volatility in the GDP series, figure 5 shows that the FCIs tend to co-move with GDP and could thus potentially contain useful information to improve the accuracy of GDP forecasts. 


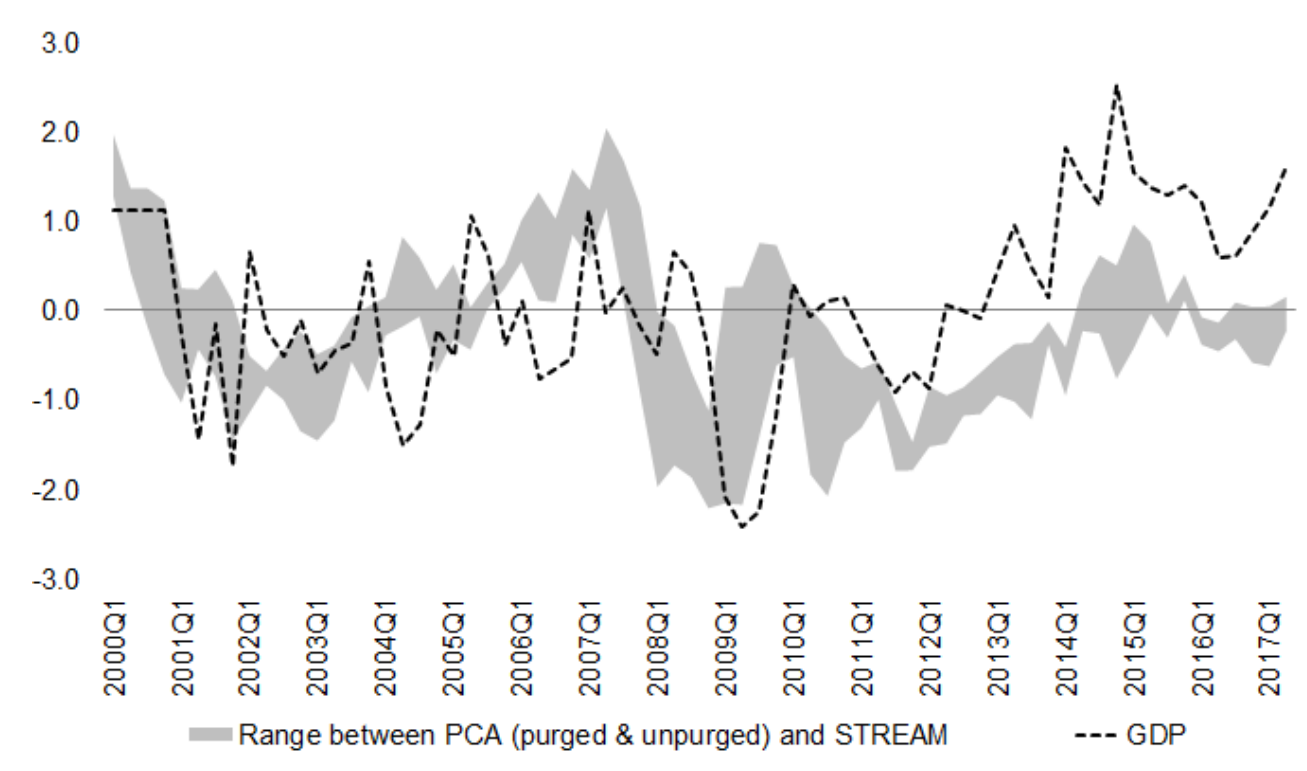

Source: Authors' Calculations

Figure 5. FCIs and GDP growth rate

(y-o-y growth rate)

By combining the information from the various financial indicators, the FCI tracks real economic activity better than most of the individual indicators. Table 1 illustrates the correlation between the three FCI indices and real economic activity, both for the entire sample period (1996-2017Q2) as well as two sub-samples (1996-2006 and 2007-2017Q2).

For the full sample, the FCI from STREAM and PCA-unpurged correlates the most with one-quarter ahead real GDP growth (ranging between 0.33 and 0.40 for $t+1$ ). By construction, the FCI-purged has no correlation with contemporaneous GDP growth and therefore the contemporaneous correlation is excluded from Table 1 .

There are noticeable differences between the two sub-periods. For instance, the PCA-based FCIs have a higher correlation in the first sub-sample. The correlation of the two PCA-based estimates with real GDP peaks at around 0.54 three-quarters ahead over the period 1996-2006. On the contrary, the FCI based on STREAM exhibits a higher correlation with GDP growth in the second sub-sample. During the latter period, the one- and two-quarter ahead correlation increased to 0.65 and 0.60, respectively. The PCA-based approaches perform less well after the crisis, with the purged PCA exhibiting very low correlation with GDP. The difference between the two reflects the effects of the exchange rate depreciation in the STREAM-FCI, which leads to a relatively faster recovery in financing conditions compared to the PCA-based estimates. 
Table 1. Correlation between FCI and Economic Activity

\begin{tabular}{|c|c|c|c|c|}
\hline \multirow[b]{2}{*}{ Period: 1996-2017Q2 } & \multicolumn{4}{|c|}{$\underline{\text { Real GDP growth (y-o-y) }}$} \\
\hline & $t+1$ & $t+2$ & $\mathbf{t}+\mathbf{3}$ & $t+4$ \\
\hline PCA_Unpurged & 0.33 & 0.27 & 0.23 & 0.12 \\
\hline PCA_purged & 0.13 & 0.17 & 0.23 & 0.20 \\
\hline STREAM & 0.40 & 0.33 & 0.30 & 0.28 \\
\hline \multicolumn{5}{|l|}{ Period: 1996-2006 } \\
\hline PCA_Unpurged & 0.45 & 0.43 & 0.48 & 0.41 \\
\hline PCA_purged & 0.39 & 0.45 & 0.54 & 0.49 \\
\hline STREAM & 0.36 & 0.29 & 0.36 & 0.36 \\
\hline \multicolumn{5}{|l|}{ Period: $2007-201702$} \\
\hline PCA_Unpurged & 0.45 & 0.35 & 0.20 & 0.10 \\
\hline PCA_purged & 0.00 & 0.07 & 0.10 & 0.11 \\
\hline STREAM & 0.65 & 0.60 & 0.49 & 0.44 \\
\hline
\end{tabular}

Finally, Table 2 shows the pairwise granger causality tests between the three measures of FCIs and GDP growth for different lag lengths. These tests show that, in general, except for the purged PCA, there is causality from the FCI to GDP growth but not the other way around.

Table 2. Pairwise Granger Causality Test

\begin{tabular}{lcccc}
\hline & \multicolumn{4}{c}{ p-values } \\
\cline { 2 - 5 } PCA-Unpurged & Lag 1 & Lag 2 & Lag 3 & Lag 4 \\
\hline Output does not Granger Cause FCI & 0.45 & 0.81 & 0.94 & 0.91 \\
FCI does not Granger Cause Output & 0.17 & 0.04 & 0.10 & 0.05 \\
PCA-Purged & Lag $\mathbf{1}$ & Lag $\mathbf{2}$ & Lag 3 & Lag 4 \\
Output does not Granger Cause FCI & 0.72 & 0.65 & 0.25 & 0.41 \\
FCI does not Granger Cause Output & 0.13 & 0.30 & 0.37 & 0.27 \\
STREAM & Lag $\mathbf{1}$ & Lag 2 & Lag 3 & Lag 4 \\
Output does not Granger Cause FCI & 0.66 & 0.56 & 0.77 & 0.89 \\
FCI does not Granger Cause Output & 0.05 & 0.02 & 0.04 & 0.08 \\
\hline
\end{tabular}

\section{Conclusion}

This article has developed an FCI for the Maltese economy using two different approaches, one using principal components and another one with the weights derived from simulations using STREAM, the macro-econometric model maintained at the Central Bank of Malta. Since Malta is a small-open economy, the FCIs include both domestic as well as foreign 
variables. The latter are meant to capture the openness of the Maltese economy and its reliance on international financial conditions.

Financing conditions exhibit a cyclical pattern in Malta. They were relatively benign in the mid-to-late $90 \mathrm{~s}$ and in the pre-crisis period. On the contrary, they were relatively tight in the early 2000s and in the aftermath of the financial crisis. All the methods indicate that financing conditions have improved since 2013, though to different degrees, reflecting differences in the indicators and weights used in these indices. Statistical tests suggest that the information contained in these FCIs can be useful for short-term forecasting.

The FCI is a tool which can easily be used by policymakers, as it is quite intuitive to understand the state of financing conditions at a particular point in time and the contributing factors. Indeed, the estimates presented here confirm that Malta's financial conditions tightened in the aftermath of the crisis, initially due to international factors but subsequently reflecting domestic factors. Policy in a small-open economy can primarily affect domestic factors, and hence macro-prudential policies in particular should focus on improving domestic financial conditions. Moreover, given that the analysis presented here suggests that financial conditions do affect economic activity, addressing this relatively domestic-inducted tightening could be beneficial to growth. In this light, recent policy initiatives that were intended to improve domestic financial conditions should help make Malta's growth more sustainable. One of these policy initiatives was the introduction of the Central Credit Register, which was intended to reduce information asymmetries in the banking sector, thereby reducing information costs, risks, and non-performing loans. The setting up of a development bank was intended to address market failure by offering financing activities where the market is unable or unwilling to do so, with a focus on SMEs and infrastructural projects.

\section{Acknowledgement}

The authors would like to thank Dr. Aaron G Grech, Chief economist at the Central Bank of Malta, for his helpful comments.

\section{References}

Angelopoulou, E., Balfoussia, H., \& Gibson, H. D. (2014). Building a financial conditions index for the euro area and selected euro area countries: What does it tell us about the crisis? Economic Modelling, 38,

38, 392-403. http://dx.doi.org/10.1016/j.econmod.2014.01.013

Bernanke, B., \& Gertler, M. (1989). Agency Costs, Net Worth, and Business Fluctuations. American Economic Review, 79(1), 14-31.

Bernanke, B., Gertler, M., \& Gilchrist, S. (1998). The financial accelerator in a quantitative business cycle framework. Cambridge, MA: National Bureau of Economic Research. https://doi.org/10.3386/w6455_ 
Bokan, N., Gerali, A., Gomes, S., Jacquinot, P., \& Pisani, M. (2018). EAGLE-FLI: A macroeconomic model of banking and financial interdependence in the euro area. Economic Modelling, 69, 249-280. http://dx.doi.org/10.1016/j.econmod.2017.09.024

Carlstrom, C. T., \& Fuerst, T. S. (1998). Agency costs and business cycles. Economic Theory, 12(3), 583-597. http://dx.doi.org/doi:10.1007/s001990050236

Christoffel, K., Coenen, G., \& Warne, A. (2008). The New Area-Wide Model of the Euro Area: A Micro-Founded Open-Economy Model for Forecasting and Policy Analysis, European Central Bank Working Paper No. 944.

Darmanin, J. (2017). The Financing of Companies in Malta. Central Bank of Malta Policy Note. Retrieved from http://www.centralbankmalta.org/file.aspx?f=61638

Darracq Pariès, M., Laurent, M., \& Diego, M (2014). Financial Conditions Index and Identification of Credit Supply Shocks for the Euro Area. International Finance, 17(3), 297-321. http://dx.doi.org/10.1111/infi.12056

Dudley, W., \& Hatzius, J. (2000). The Goldman Sachs Financial Conditions Index: The Right Tool for a New Monetary Policy Regime. Global Economics, Paper No. 44.

English, W., Tsatsaronis, K., \& Zoli, E. (2005 Assessing the predictive power of measures of financial conditions for macroeconomic variables. In Investigating the relationship between the financial and real economy. Bank for International Settlements.

Freedman, C. (1995). The role of monetary conditions and the monetary conditions index in the conduct of policy. Bank of Canada Review, 53-59.

Gauthier, C., Graham, C., \& Liu, Y. (2004). Financial Conditions Indexes for Canada. Bank of Canada Staff Working Papers 04-22.

Gerali, A., Neri, S., Sessa, L., \& Signoretti, F. M. (2010). Credit and Banking in a DSGE Model of the Euro Area. Journal of Money, Credit and Banking, 42, 107-141. http://dx.doi.org/10.1111/j.1538-4616.2010.00331.x

Gertler, M., \& Karadi, P. (2011). A model of unconventional monetary policy. Journal of Monetary Economics, 58(1), 17-34. http://dx.doi.org/10.1016/j.jmoneco.2010.10.004

Goodhart, C. (2001). What Weight Should be Given to Asset Prices in the Measurement of Inflation?, De Netherlandsche Bank Staff Report No. 65.

Goodhart, C., \& Hoffman, B. (2000). Financial Variables and the Conduct of Monetary Policy. Sveriges Riksbank Working Paper No. 112.

Grech, O., \& Rapa, N. (2016). STREAM: a structural macro-econometric model of the Maltese economy. Central Bank of Malta Working Paper WP/01/2016.

Guichard, S., \& Turner, D. (2008). Quantifying the Effect of Financial Conditions on US Activity. OECD Economics Department Working Papers No. 635.

Guichard, S., Haugh D., \& Turner, D. (2009). Quantifying the Effect of Financial Conditions 
in the Euro Area, Japan, United Kingdom and United States. OECD Economics Department Working Papers No. 677.

Gumata, N., Klein, N., \& Ndou, E. (2012). A financial conditions index for South Africa. IMF Working Paper WP/12/196.

Hakkio, C., \& Keeton, W. (2009). Financial stress: What is it, how can it be measured, and why does it matter? Economic Review, Federal Reserve Bank of Kansas City.

Hatzius, J., Hooper, P., Mishkin, F., Schoenholtz, K., \& Watson, M. (2010). Financial Conditions Indexes: A Fresh Look after the Financial Crisis. National Bureau of Economic Research. https://doi.org/10.3386/w16150

Ho, G., \& Lu, Y. (2013). A financial conditions index for Poland. IMF Working Paper $W P / 13 / 252$.

Hollo, D., Kremer, M., \& Lo Duca, M. (2012). CISS- A composite indicator of systemic stress in the financial system. European Central Bank Working Paper No. 1426.

Kiyotaki, N., \& Moore, J. (1997). Credit Cycles. Journal of Political Economy, Vol. 105(2),

Manning, J., \& Shamloo, M. (2015). A Financial Conditions Index for Greece. IMF Working Papers WP/15/220

Mayes, D. G., \& Viren, M. (2002). Financial Conditions Indexes. Bank of Finland Working Paper No. 17/2001

Micallef, B. (2015). Estimating a Credit Gap for Non-Financial Corporations in Malta. Working Paper WP/04/2015, Central bank of Malta. Retrieved from https://www.centralbankmalta.org/file.aspx?f=11219

Micallef, B. (2016). A financial stress index for Malta. Central Bank of Malta Quarterly Review, 2016(2).

Micallef, B. (2018). Constructing an index to examine house price misalignment with fundamentals in Malta. International Journal of Housing Markets and Analysis, 11(2), 315-334. https://doi.org/10.1108/IJHMA-11-2017-0099

Micallef, B., Noel, R., \& Tiziana, G. (2016). The role of asymmetries and banking sector indicators in the interest rate pass-through in Malta. Journal of Advanced Studies in Finance, $\quad$ VII(1), 13th $\quad$ ser. $\quad$ Retrieved from https://journals.aserspublishing.eu/jasf/article/view/494

Osorio, C., Unsal, D. F., \& Pongsaparn, R. (2011). A Quantitative Assessment of Financial Conditions in Asia. IMF Working Papers, 11(170), 1. https://doi.org/10.5089/9781462314331.001

Quadrini, V. (2011). Financial frictions in macroeconomic fluctuations. Economic Quarterly, Issue 3, Federal Reserve Bank of Richmond,209-254. Retrieved from https://www.richmondfed.org/publications/research/economic_quarterly/2011/q3/quadrin 
i

Smets, F., \& Wouters, R. (2003). An Estimated Dynamic Stochastic General Equilibrium Model of the Euro Area. Journal of the European Economic Association, 1(5), 1123-1175. https://doi.org/10.1162/154247603770383415

Stock, J. H., \& Watson, M. W. (2002). Forecasting Using Principal Components from a Large Number of Predictors. Journal of the American Statistical Association, 97(460), 1167-1179. https://doi.org/10.1198/016214502388618960

Swiston, A. (2008). A U.S. Financial Conditions Index: Putting Credit Where Credit is Due. IMF Working Papers WP/08/161

Wacker, K., Lodge, D., \& Nicoletti, G. (2014). Measuring financial conditions in major non-euro area economies. European Central Bank Working Paper No. 1743.

Zerafa, S. (2016). Survey on access to finance (SAFE) in 2015. Central Bank of Malta Quarterly Review, 2016(1).

\section{Copyright Disclaimer}

Copyright for this article is retained by the author(s), with first publication rights granted to the journal.

This is an open-access article distributed under the terms and conditions of the Creative Commons Attribution license (http://creativecommons.org/licenses/by/3.0/). 